Ethnographic Writing, the Avant-Garde and a Failure of Nerve Author(s): Paul Atkinson

Source: International Review of Qualitative Research, Vol. 6, No. 1 (Spring 2013), pp. 19-35

Published by: University of California Press

Stable URL: http://www.jstor.org/stable/10.1525/irqr.2013.6.1.19

Accessed: 05/03/2014 09:43

Your use of the JSTOR archive indicates your acceptance of the Terms \& Conditions of Use, available at http://www.jstor.org/page/info/about/policies/terms.jsp

JSTOR is a not-for-profit service that helps scholars, researchers, and students discover, use, and build upon a wide range of content in a trusted digital archive. We use information technology and tools to increase productivity and facilitate new forms of scholarship. For more information about JSTOR, please contact support@ jstor.org. 


\title{
Ethnographic Writing, the Avant-Garde and a Failure of Nerve'
}

\section{Paul Atkinson}

\begin{abstract}
The paper reminds us that there has been a long history of mutual influence between ethnography and aesthetics. There is nothing new or recent in textual or graphic experimentation inspired by anthropological or sociological fieldwork. We have not had to wait for the so-called crisis of representation to acknowledge this. Anthropology was among the direct sources and inspirations for modernist aesthetics and textual practice. I go on to suggest that too many contemporary forms of textual experimentation are in fact lacking in truly experimental, avant-garde, force. We need collectively to revisit the values and practices of modernism. I suggest that too many contemporary texts display sentimental realism, a preoccupation with feelings and personal experiences, grounded in realist forms of biographical or autobiographical writing. This represents, I shall suggest, a collective failure of nerve. I call for more disciplined forms of experimentation that are more relevant to a modernist sensibility as well as more faithfully ethnographic.
\end{abstract}

Keywords: ethnography, aesthetics, modernism, sentimental realism, autoethnography

\section{Introduction}

I challenge some of the prevailing tendencies in textual practices among ethnographers and other qualitative researchers. I suggest that far from being radically innovative, many of these practices are in fact conservative in effect. My criticisms are, therefore, not based on an appeal to past conventions or a rejection of experimentation. On the contrary, my position is more radical than most, and I accuse the research community of a collective failure of nerve. In other words, I celebrate the intersection of ethnography, aesthetics, and the avant garde, but I also maintain that too much of the "new ethnography" remains locked within a set of conservative textual conventions.

International Review of Qualitative Research, Vol. 6, No. I, Spring 2013, pp. 19-36.

ISSN 1940-8447, eISSN 1940-8455. (c) 2013 International Institute for Qualitative Research,

University of Illinois, Urbana-Champaign. All rights reserved. Request permission to photocopy or reproduce article content at the University of California Press's Rights and Permissions website at http://www.ucpressjournals.com/reprintinfo.asp. DOI: 10.1525/irqr.2013.6.1.19. 
Consequently, I commend a better informed approach to ethnographic practice that acknowledges and builds on virtually a century of potential influences. In doing so I also suggest that appeals to "postmodernism" are misleading and misplaced, as modernism's tradition furnishes pertinent exemplars, while postmodernism is a red herring in this context.

I start this argument from somewhere familiar to me and - I hope and trust unfamiliar to most of my readers. Denis Williams (1923-1998) was a scholar known to too few ethnographers and others. Williams was, and remains, a figure of considerable interest. He was a painter and sculptor, an author of fiction, an anthropologist, and an archaeologist. He moved widely - geographically, culturally, and intellectually. He was Guyanese by birth. He lived and painted in London, at one time sharing a studio with Francis Bacon, a now infinitely more famous artist (E. A. Williams, 2012; Williams \& Williams, 2010). He undertook anthropological and archaeological work in Africa, working among other things on the iconography of classical African art (D. Williams, 1974). He wrote two novels that were regarded as among the most significant of those by postwar Caribbean authors (D. Williams, 1963/2009, 1968/ 2010). He spent part of his life in Wales, where his family went on living. He returned to his native Guyana, where he founded the country's national museum and was a major figure in the development of Guyana in its postcolonial years.

Williams had, therefore, a remarkable combination of intellectual pursuits. For my purpose he is an especially interesting figure; he combines anthropological scholarship with authorship of innovative fiction. His two novels each pose a particular kind of problematic. The first, Other Leopards (1963/2009), is set in a fictionalised Sudan (where Williams himself worked) and explores the problematic identity of its central character, a Caribbean man who is working on Africa past, in the form of Meroitic archaeology, while confronting Africa present, in the form of nationalist politics. It moves from a realist narrative to a possibly surreal conclusion. The second novel again focuses on the Caribbean outsider but is set in Wales, where Williams himself lived. In partial contrast to much of Other Leopards, The Third Temptation $(1968 / 2010)$ is a thoroughly modernist work of fiction. Within a tightly restricted time-frame and starting from an otherwise unexplored accident, Williams explores multiple perspectives in a deliberately fragmented, allusive, nonlinear text. It is quite clearly influenced by avant-garde, modernist genres in fiction and cinema.

I have briefly summarised aspects of Williams's work for two reasons. First, as a corpus of work it quite simply deserves to be better known. Secondly, and of course much more importantly for my argument, it exemplifies the intersection of a visual aesthetic, a literary aesthetic, and an anthropological sensibility. But I also use the 
example of Denis Williams to introduce a more general point. Williams is but one among many authors who have drawn together threads of anthropology and literature with visual and plastic arts to create richly patterned fabrics of text and artefact. The relationships between the ethnographic and the aesthetic have long histories. They reflect a variety of different national and philosophical traditions. The relationships between archaeology, ethnography, modernism, and the arts take multiple paths.

\section{Ethnography, anthropology, and modernism}

There have been multiple strands of mutual influence between anthropology (in the broadest sense) and aesthetics. They also include archaeological inspirations (as is the case with Denis Williams). Gere (2009) has explored how the archaeology of Minoan Crete by Arthur Evans contributed to a modernist aesthetic and also to a number of key modernist thinkers. For instance, the poets Robert Graves and Hilda Doolittle (H.D.) were thoroughly influenced by both the archaeology of bronze-age Crete and of anthropological theories concerning the Mother-Goddess. Modernist art and design have frequently made reference to "exotic" forms and inspirations. The impact of African plastic art on emergent modernism in European painting and sculpture is well known and well documented. Kelly (2007), for instance, explores the significance of the French Dakar-Djibouti expedition on the arts in Paris in the 1920s and 1930s. Surrealist artists and authors such as Michel Leiris were directly inspired by anthropological discoveries. French intellectuals were affected by images of primitivism and "negritude." Leiris inhabited intellectual spaces reflecting African anthropology, surrealism, and modernism, and there was an important convergence between the anthropological and the surrealist imaginations (Clifford, 1981, 1988).

The mutual influences between the ethnographic and literary imaginations have been multiple and have been documented from a variety of perspectives. (These are parallel to but independent of the specifically modernist strands.) In the contemporary fashion for "new" ethnographic writing, however, we all too often find a shallow sense of history, as if a literary sense of the ethnographic were a distinctively novel sensibility.

In the United States, of course, authors such as Ruth Landes and Zora Neale Hurston are among the significant figures in the history of anthropological writing for whom literary and aesthetic values featured strongly and whose work clearly transcends simplified boundaries of genre. And yet they are not visibly at the core of a canon of texts that contemporary exponents of "the new ethnography" or "blurred genres" routinely reference as benchmarks in the history of ethnographic writing. 
These histories of literature and ethnography may be supplemented by many commentaries on literature and the ethnographic imagination, which include Evans's (2005) analysis of the intersections of ethnography and literature in the prehistory and early years of American cultural anthropology and Capetti's (1993) valuable exploration of forms of writing in and about Chicago that is a classic treatment of the subject. Capetti points out the intellectual parallels between the early urban sociology of the Chicago School and the distinctive forms of realist or naturalistic fiction that were also characteristic of Chicago and its environs. Both display a certain sense of personal development and change, set against an urban landscape of rapid social transformation. The novels of, say, Theodore Dreiser, James Farrell, or Upton Sinclair trace the same contours of personal development and social change as do the classic works of sociologists such as Paul Cressey, Harvey Zorbaugh, or Frederick Thrasher. The intersections of ethnography and aesthetics have, in other words, a long history. Since the rediscovery of feminist and "literary" antecedents, the anthropological writings of Zora Neale Hurston and Ruth Landes, for instance, have benefited from a revival and the publication of critical commentaries. Their work mingled an anthropological and a literary sensibility: They prefigured contemporary interests by several decades (Cole, 1995; Hernández, 1993). While it would be quite wrong to attribute all of these to a distinctively modernist aesthetic, it is clearly the case that we have not had to wait until the "postmodernist" turn for a recognition of "literary" forms of ethnographic reportage. To summarise my observations so far: There is nothing new in an aesthetics of ethnography. Indeed, from realist roots through surrealist and modernist developments, ethnography has always enjoyed a close affinity with diverse forms of literary and artistic representation.

\section{The fate of modernism}

Now I want to take as a point of departure a recent book by Josipovici (2010) in which he takes to task contemporary fiction - notably in Britain - and asks whatever happened to modernism as a literary movement. He suggests that a great deal of contemporary fiction - notably, perhaps, the most high-profile work of well-known novelists - has lost connection with the innovative and experimental aspects of modernist fiction. His argument is focused primarily in English-language fiction from the United Kingdom, and I do not adopt it assuming that it applies equally to all contemporary fiction. But I do find Josipovici's argument can usefully be extended to encompass contemporary texts of qualitative inquiry of a certain sort. I want to argue, in other words, that too much of the "new ethnography" as a textual genre 
has also lost connection with the possibilities of avant-garde literary experimentation. The possibilities of modernism, in its many forms, seem to have lost sight, while appeals to postmodernism too often result in new forms of naturalism.

There is, of course, no single modernist genre. But it is worth pausing to remind ourselves what modernism gave us. Its distinctive literary, formal properties included disrupting taken-for-granted narrative formats; the fracturing of temporal and perspectival frames; multiple and/or ambiguous points of view within the text; a close attention to the detailed description of material circumstances; and multiple voices and idioms in the text. The modernist text is clearly artful, in that its artifice is apparent. It is, in Barthes's terms, a writerly text rather than a readerly one. It makes no gesture towards a transparent, untroubled representation of mundane reality. Instead, it engages in a hyper-realist form of description, a stream-ofconsciousness narrative mode, or a montage of textual forms and sources. One need only to think of the literally extraordinary effects of James Joyce's Finnegan's Wake to appreciate that such a modernist masterpiece is far removed from the canons of readability and narrative development characteristic of the realist novel.

This is, of course, an extreme example, and modernism does not have to be quite so impenetrable. Virginia Woolf's fiction is more directly readable, for all that it also eschews simple forms of narrative realism. Equally, the work of John Dos Passos, such as the monumental USA, encompasses narratives, multiple perspectives, slogans, and newspaper headlines. It recapitulates the diversity and vigour of American life itself through a fragmented and multiple set of textual conventions. Recent discussions surrounding the production of an edition of William Faulkner's The Sound and the Fury in multiple colours (an idea that originated with the author) designed to highlight the different narratives in play has served to remind us of the phenomenological complexity of such a modernist text. Modernist texts destabilise. They withhold temporal or spatial frames that can be taken for granted. They do not admit of simple narrative threads but weave densely interlocking - often confusing or troubling - narrations. They also destabilise character. In contrast to the realist novel, they do not present a set of stable, unproblematic characters. The subject of modernism can itself be as fragmented and as problematic as any other textual device. Modernism in this sense has absolutely nothing to do with modern science, positivist social science, or any similar associations. Indeed, it is their antithesis.

Modernism, in other words, is a form of highly intellectual representation. It disrupts the surfaces of everyday, taken-for-granted assumptions about representation. In contrast, Josipovici (2010) argues, too many contemporary novelists have turned their back on the achievements of modernism in favour of realist, naturalistic 
narratives, often based on first-person or single-perspective narratives. These are highly readerly works of fiction, mostly with little intellectual pretension. This is an argument levelled especially at a generation of English novelists and is not intended to characterise a universal trend. Nevertheless, Josipovici's argument is a useful point of reference for me, for I want to argue that there is a similar process at work in the recent and current attempts to develop various forms of ethnographic fiction and alternative forms of ethnographic text. The English writers of fiction have embraced what I want to call a form of sentimental realism. That is, a style of writing that is characterised by two things simultaneously. First, a realist style of writing in which nothing disrupts or reflects upon the text's surface. Second, a preoccupation with a narrative of feelings. It makes little or no difference whether the fictions in question are couched in first-person or third-person modes, incidentally. It seems to me that there is a very similar tendency afoot among a number of writers of new ethnographies and genres of personalised experience that are aligned with qualitative research strategies. Moreover, modernism is in no way to be aligned with simplistic modes of representation; it has no affinity with positive science or naively realist writing.

As we have seen, there was a convergence of perspectives, informed by a variety of intellectual traditions that agreed the mainstream of ethnographic writing was open to criticism. Derived from literary theory, the rhetoric-of-inquiry programme, and other traditions, authors developed a broad programme of critique. It included the following elements:

- Ethnographic texts too often presented a monologic view of ethnographic inquiry, privileging the uniquely knowing observer.

- Ethnographic texts incorporated realist or naturalistic textual conventions. They therefore masked their own facticity, presenting themselves as transparent representations of an independent social reality.

- The ethnographic observer and the ethnographic author were, therefore, written out of the texts.

- The ethnographer-as-author was, in consequence, endowed with a particular degree of authority.

- The realist texts of mainstream ethnography were insufficiently sensitive to the complexities, the ruptures, and the diversities of everyday social life.

These observations did not derive exclusively from the critiques of anthropological writing, from within anthropology itself. The collection of papers edited by Clifford and Marcus (1986) was certainly influential, and its influence spread beyond 
the confines of anthropology alone. Behar and Gordon (1995) provided a feminist contribution, arguing that many women anthropologists had rejected the canonical textual styles of their contemporaries and experimented with "other" literary forms. A collection of responses by British social anthropology was edited by James, Hockey, and Dawson (1997). From within sociology, however, there had already been textual commentaries on the conventions of realist ethnographic writing. Atkinson (1983, 1990, 1992, 1996) specifically addressed the textual conventions of sociological ethnography, particularly - but not exclusively - urban and organisational ethnography. Pointing out, in common with Carey (1975), the mutual influences of ethnographic research and the interactionist tradition, Atkinson (1983) focused on the irony that although interactionism was founded on a recognition of how language is constitutive of social reality, interactionists seemed to pay insufficient attention to their own written language. There seemed to be a disjuncture between the sensitivities of ethnographic fieldwork and the relative insensitivity of interactionist writing.

Van Maanen (1988) authored an incisive analysis of the different genres of ethnographic writing, highlighting contrasts between conventional, realist ethnographic texts and the confessional mode of autobiographical narrative. These specifically ethnographic commentaries developed arguments that had been outlined more generically in relation to the conventions of sociological argument. Brown (1977) argued that an understanding of sociological argumentation rests on an analysis of its rhetorical forms, while Anderson (1978) brought an ethnomethodological perspective to bear on sociological argument. In a similar vein, Edmondson (1984) explored some of the rhetorical forms of sociological writing, including some of the textual features of ethnographic representation.

By no means were all of these, and similar, works normative. They analysed the textual conventions that were characteristically deployed. They were not necessarily critical, except insofar as there was general agreement that insufficient attention had been paid to textual forms of sociological and ethnographic writing. The suggestion was that this represented incomplete reflexivity: While ethnographers in particular were committed to the analysis of reality-construction, they were insufficiently sensitive to their own practices of reality reconstruction (Atkinson, 1990).

As a consequence of all this activity, it has become far more common for ethnographers and other qualitative scholars to embrace a self-conscious approach to their textual productions. This has been associated with various calls for textual experimentation, the use of different genres, the blending of genres, and the adoption of explicitly literary forms. These have included: 
- A greater propensity to write the author "into" the ethnographic text so the processes of inquiry and authorship are simultaneously available to the reader.

- An acknowledgement of the analytic opportunities afforded by "messy texts" that challenge the smoothly realist surfaces of more traditional texts.

- A willingness to adopt more overtly "literary" forms of text to create distinctive representational effects.

These have included various forms of autobiographically based writing, generically referred to as autoethnography, as well as the production of ethnographic fictions, the authoring of ethnodrama, the use of verse forms, and indeed a wide variety of textual forms.

Here we come to the crux of my argument. It is my contention that too many contemporary authors who claim to endorse textual experimentation in effect display a failure of nerve. To put the argument in a nutshell, instead of a thoroughly modernist embrace of textual experimentation and multiple textual forms, in fact we have far too many texts that display what I have previously referred to as romantic or sentimental realism, that is, an undue emphasis on narratives of personal experience that celebrate the personal and stress a storied, readerly textual form. This does not mean, of course, that there have been no significantly experimental texts, and I shall return to some of them in a little while. But I want to dwell on the contemporary genres of qualitative inquiry that include - but are not exhausted by - socalled autoethnographic writing.

What is my problem with such writing? Before I outline that, let me briefly summarise what seems to me to be broadly agreed positions among ethnographers and others engaged in writing qualitative inquiry.

- All textual forms are conventional, and there is no single "natural" form that is independent of such conventionality.

- Writing is itself a form of analysis. It is a mode of reconstructing the social worlds that we study.

- Writing is never a neutral medium of representation and is always implicated in the arguments and analyses that it embodies.

- As analysts, we have to take responsibility for the formal choices we make in terms of written texts (and other representations).

- It is possible to do justice to the forms of social life through distinctive forms of ethnographic writing.

- There is nothing "natural" about linear, monological ethnographic texts. 
- Messy texts and alternative genres can be productive of major sociological and anthropological insight.

In the contemporary methodological climate, we might want to add something further about the ethnographic enterprise itself. In particular, we should add in a recognition of the essential multimodality of everyday life and culture - visual, sensory, spoken, embodied, and so on. Consequently, we might add that our forms of reconstruction and representation can go beyond textual forms per se to include multiple modalities of representation, notably visual and auditory (cf. Hurdley \& Dicks, 2011). Digital technologies of data collection and reconstruction create such opportunities in abundance (see Dicks, Mason, Coffey, \& Atkinson, 2005).

It seems to me that the current vogue for certain styles of fictionalised or autoethnographic texts display a recurrent failure of nerve in this respect. They are, perhaps, "experimental" in the sense that they do not present themselves as conventional forms of academic writing, as papers or monographs. But equally, the failure of nerve I allude to resides in the embrace of a restricted set of textual practices that are the reverse of modernist experimentation. They revert to conventionally realist or naturalistic writings, often based on personal experience and feelings that do little justice to the potential of truly experimental texts. Moreover, these contemporary textual types often appeal to an emotional response in the reader rather than inviting an intellectual, analytic engagement. To that extent, therefore, they are reductionist in (literally) reducing social life to an experiential dimension.

It would be perverse as well as unjust of me to suggest in this paper that individual contributions to this genre are unsuccessful in their own terms, or that they do not have powerful effects on their readers. Key authors and key works include Richardson (1997) and Ellis (2004), who have made sustained contributions to the genre itself as well as significant contributions to the methodological literature advocating such textual approaches. They have also contributed literary texts of considerable significance. Equally, in this general paper I do not want to engage in invidious criticisms of individual pieces of writing, preferring to conduct the argument at a more general level. Consequently, I shall pursue this theme through texts about textual strategies of the new ethnography and personal, autoethnographic writing.

Goodall (2000) is a useful point of departure in that he provides an accessible source that expresses some of the principles of the "new" ethnographic writing in a lucid fashion. While he acknowledges the contributions of some predecessors, it is noticeable that - in confirmation of my own thesis - his book is more or less silent on the long tradition of anthropological writing; it would, yet again, be possible to infer 
that interest in such literary issues was a recent invention. More significantly, Goodall clearly stresses the centrality of writing about the "self" (that is, the ethnographerauthor). Indeed, it is, apparently, an imperative: "new ethnographers have an obligation to write about their lives" (p. 23). Now it is not at all clear to me that there is such an obligation, but there is a more fundamental issue: how that self is conceptualised and therefore how it is written into the text.

The collection of papers edited by Ellis and Bochner (1996) represent a nowclassic series of statements from authors that include leading exponents of the genre, including the editors themselves. It is, of course, not easy to derive from the editorial matter a straightforward statement of their position, as it is couched in the form of a dialogue between Ellis and Bochner themselves.

The so-called "crisis of representation" that created something of a furore in anthropological circles included reflection on the position and voice of the ethnographer-as-author. The substance of the shared criticism was as follows. The standard realist style of the classic ethnographic monograph implicitly positioned the ethnographer as an omniscient observer. There was but one viewpoint, one perspective - that of the anthropologist. The implication of that critique was that the ethnographic text should in consequence have a multiperspective arrangement, a polyvocalic quality. But in the rush to write (literally) self-centred texts, we run the risk of a new form of monologism. The cool eye of the observer has been replaced by emotionally laden experiences. The authorial self is no longer a detached observer of others' actions but an involved participant in her or his own personal life.

At root, therefore, we are presented with a Romantic subject. The self that is implicitly inscribed in these texts of "new ethnography" is not one conceived in sociological terms. On the one hand, sociological analysis implies that we must think in terms of a social actor, performative in character, constituted by a variety of practices - linguistic and otherwise. But in its emphasis on the writing of personal experience, the new ethnographic text posits a subject of interior subjectivity, a relatively stable "self." Now this is not the self of symbolic interactionism, or of Goffman's version of microsociology. It is certainly not a self of either modernism or postmodernism. Indeed, there is a paradox at the heart of too much contemporary ethnographic work. It pays lip service to a plastic, fragmented, socially constituted view of the social self but endorses a completely different view of the self of the ethnographer-as-author. For instance, Neumann (1996) gives a succinct justification for this view.

Autoethnography renames a familiar story of divided selves longing for a sense of place and stability in the fragments and discontinuities of modernity. 
Writing and reading such stories has long been a means of collecting ourselves, of seeking order and meaning in a world that often conspires against continuity. (pp. 173-174, emphasis in original)

Such a search for ontological security is antithetical to the sociological or anthropological imagination. In a quite different vein, but with an equivalent force, Richardson's (1996) autobiographical fragment in the same volume suggests a recuperative move in the reclamation of an authentic "self" in contrast to various forms of dramaturgical enactment over the course of a life and academic career. Again, such a contrast is fundamentally at odds with a sociological understanding of everyday life and its performativity. Characteristic, too, is the programmatic, if personally expressed, statement by Quinney (1996), where he suggests that writing an ethnography about an early episode in your life "will encompass your emotional and spiritual life, your very being" (p. 357). And he goes on in a very telling phrase, that "this is ethnography as the lived experience of the ethnographer" (p. 357). It may well be a deeply felt personal memoir, but whether it is ethnography in the sense intended by sociologists and anthropologists is a different matter. The resulting text, however, certainly satisfied my criterion for sentimental realism.

Of course, these are but fragmentary examples from a large and varied corpus. There are various textual strategies in play, and some texts are more transgressive or exploratory than others. For the most part, however, the texts, whether described as ethnography, autoethnography, or performance pieces, stick fairly closely to the tropes of conventional creative writing. There is a considerable emphasis on personal recollection, on the evocation of feelings (often highly charged and painful), and on the exploration of characters (often close to the narrator). A story rather than an analytic theme is also characteristic. Narrative coherence is valued over modernist ambiguity and parallels the quest for authorial selfhood.

\section{Some Exemplary Texts}

So far, then, I have argued that ethnographic texts of feelings, experience, and autobiography are but an incomplete realisation of ethnography's textual possibilities. My argument is not that they are "wrong" in any sense; indeed rightness and wrongness seem completely inappropriate criteria in any event. Rather, I suggest that they are restricted versions of what is possible. That is so for two reasons. First, the repeated emphasis on the experiential robs the texts of many other analytic possibilities. Second, the autobiographical (autoethnographic) mode reduces the potential scope 
of textual experimentation. The cumulative consequence is a paradoxical lack of textual experimentation. This is coupled with a further danger that is a form of narrative or rhetorical reductionism. Texts of personal experience - whether factual or fictionalised - are too often constructed in terms of a naturalism that denies the potential complexities of the social self and of social encounters and indeed of the multiple modalities of everyday life (Atkinson, Delamont, \& Housley, 2008).

I continue with a discussion of one particular text that seems to me to exemplify at least one powerful possibility in textual experimentation. I do so precisely because it seems to be relatively little known, and yet it deserves close attention. I take the case of Dalby, whose range of textual devices is remarkable and who seems to be operating outside the ambit of contemporary exponents of the new ethnography and its compositional styles. She has worked as a geisha in Japan and wrote a fairly conventional ethnographic account of that period (Dalby, 1983). I say it is fairly conventional advisedly. Dalby's involvement with the work and the world of geisha was more engaged than would be the case for many ethnographic undertakings. For my purposes, however, it is the other texts that she has produced in parallel that are of more direct interest. A fictional account of a mediaeval Japanese noble lady (2000) exploits Dalby's historical and anthropological scholarship, but - more importantly - uses the literary conventions of such courtly diaries themselves in constructing the fiction. In other words, the indigenous literary conventions are drawn on, not just the conventions of English-language realist fiction. In the same vein, Dalby has also written a yearbook based equally on indigenous Japanese textual forms (2007). In other words, the forms of textual reconstruction mirror the forms of the cultural in question itself. Clearly when dealing with a culture as highly contrived as Japan, this is a significant mode of fidelity to the original cultural phenomena.

Now several things seem to follow from this. In the first place, it displays a considerable literary imagination. It also calls for a considerable degree of intellectual discipline. One has to work pretty hard to master such a literary style sufficiently well to be able to reproduce it. Secondly, the textual format has an analytic point. It is not gratuitous. It reflects an understanding of indigenous cultural, expressive forms. It is clearly artful in that its textual artifice is clearly apparent. Now this is not an especially modernist text in itself. But it does point towards various significant possibilities. In recent years there has been increasing emphasis on so-called indigenous research methods. In parallel with such methods of research, we need more sustained explorations of modes of writing and representation that also pay due regard for indigenous and local forms of cultural formation. 
Almost precisely the same comments can be made about Tobias Hecht's work. Hecht (2006) has taken materials derived from his fieldwork in Brazil and, basing the work on the narrations of Bruna Verissimo, has constructed a fictionalised account in the form of a Latin American testimonio. An indigenous form is therefore developed in the service of ethnographically inspired fiction. Given that the testimonio is normally granted special evidential warrant because it is a first-hand, first-person account, fictionalised testimonio has a particular frisson. Even if it is not modernist in itself, therefore, the example points us in a useful direction. I want to conclude by suggesting that it is a more fruitful intellectual exercise than many current versions of writing within the communities of qualitative research.

The problems I perceive derive in part from a very limited view of what ethnographic (or qualitative) research is all about and, consequently, of what the resulting texts ought to achieve. The problem derives from an undue emphasis on the description of social actors' personal experiences and the desire to represent a social world from the participant's point of view. At first blush there may seem to be little to quarrel with here. And yet an emphasis on experience and perspective is an unduly restrictive - indeed reductionist - view of social research. It fails to give sufficient attention to the investigation of the multiple, complex modes of social action spoken, embodied, symbolic - and equally complex modes of social and cultural organization - material, semiotic, discursive (see Atkinson, Delamont, \& Housley, 2008).

In other words, we need complex representational texts that are modernist in sensibility and that self-consciously explore textual conventions in the pursuit of analytic complexity and theoretical fidelity to the social and cultural forms that are reconstructed through them. Unfortunately, too often what we find in the contemporary field is a series of biographically grounded, experientially derived narratives that attempt primarily to represent "experience" in an under-theorised view of what constitutes experience itself and what lies beyond experience in the teeming complexity of social life.

Consider a very recent case in point. Taussig (2011) has just published a short work in which he takes hastily scribbled drawings in his field notebooks as his point of departure. This is a work that has explicit links to William Burroughs, Walter Benjamin, Sigmund Freud, and Marcel Proust. It is a work of memory, but the notebook is not a diary in the strictly personal sense of the term. The complexities of engagement with the text, the palimpsests of recall and revision, the physicality of the representation itself - these are all quite different topics from the personal confessional of so many ethnographic reflections and remembrances. 
These texts therefore point to a number of different possibilities. They are not necessarily uniformly modernist in style, but they undoubtedly go beyond conventional narratives of memory, personal experience, and sentiment. They serve to remind us that "alternative" literary styles are not exhausted by the highly familiar literary models of short fiction or drama. In particular, they encourage us not to apply a new kind of uniformity to ethnographic texts; replacing the single voice of the impersonal author by the single voice of the emotionally charged narrator is no great advance.

\section{Discussion}

I have deliberately refrained from singling out particular authors for criticism in this context, as I do not wish to engage in the appearance of ad personam arguments. In any event, there are certainly achievements in this genre that I admire for their wit and inventiveness. I do, however, want to conclude by bringing this into sharper focus. It seems to me that far too much so-called ethnographic fiction and autoethnography falls into the same trap as the one identified by Josipovici (2010) in the context of recent British fiction. It is too facile, stylistically speaking. It includes far too much emphasis on the feelings and personal experiences of the actual or implied narrator. It does not challenge textual assumptions. It does not subvert taken-for-granted categories of time and place, of personhood and agency. Of course, it may challenge taken-for-granted forms of academic reportage, but that is a different matter.

To put it another way, too much contemporary ethnographic fiction, and autobiographical reflection, is too rooted in its own mundane forms of reality construction. Personal narrative is valuable up to a point, but it also has profound limitations. It does not allow us to explore the full analytic possibilities of ethnographic writing. Our task as social scientists is not merely to conjure up and evoke social worlds and situations. It is not enough to give our readers vicarious experiences, however vividly reconstructed. What I have referred to as sentimental realism carries a number of problems. Two main issues are the failure of textual nerve and the emphasis on the expression of experience. These are inter-related but not inseparable. Indeed, one could argue that modernism's various textual possibilities would be especially suited to the expression of personal experience. The internal dialogue of "stream of consciousness" fiction (found in the novels of Virginia Woolf) would, for example, provide ample exemplars for the exploration of interiority and subjective experience. The multiple time frames of the modernist novel can also reflect the temporal as well as the spatial kaleidoscopes of everyday life. 
My point here is not to advocate writing pastiche versions of modernist fiction. That is clearly a pointless exercise. My recommendation is, rather, that authors who wish to engage in "experimental" writing need to take account of a wide diversity of textual conventions. Narrative realism and sentimental realism are by no means the only literary forms, and they are not the only ways of representing social phenomena.

This brings me to my second point, which relates back more generally to the very nature of social research. As I have implied, it seems to me that far too much contemporary work is devoted to the recuperation of personal experience - sometimes the author's own (as in autoethnography) or the reported experiences of others (through the collection of interview materials). And yet, as has been argued elsewhere, this is not the sole - or even the principal - goal of social research. Such approaches pay far too little sustained attention to the enduring preoccupations of social research (Atkinson, Delamont, \& Housley, 2008). A focus on personal experience diverts attention from analytic focus on modes of social organization, on social action, on the forms of representation, and indeed all of the forms and types of collective activity. In other words, we need to recognise and reinforce the analytic issue that social life is itself conducted through multiple modes of organisation and representation. It does not follow with absolute necessity that the analysis and representation of social life must itself always be multimodal, but it does mean that textual or narrative reductionism - the adoption of a single textual form - is not in itself adequate. Or, at least, it means that the reduction of social life to a narrative expression of experience is severely limited. We need to do justice to the multiple modes of social action and social organisation that define any given social world. We ought, therefore, to avoid condensing the varieties of the social world into first-hand confessional modes, essentially realist in tone, based upon an unsociological view of the interiority of the individual subjective self. Equally, we need to turn outwards to explore more systematically and more analytically the variety of representational and formal modes of organisation - textual, visual, sonic - that inhabit the social worlds we engage with.

\section{Notes}

1. This is a revised version of a plenary talk given May 17, 2012, at the Congress of Qualitative Inquiry at the University of Illinois at Urbana-Champaign.

\section{References}

Atkinson, P. (1983). Writing ethnography. In H. J. Helle (Ed.), Kultur und Institution (pp. 77-105). Berlin: Dunker und Humblot. 
Atkinson, P. (1990). The ethnographic imagination: Textual constructions of reality. London: Routledge.

Atkinson, P. (1992). Understanding ethnographic texts. Newbury Park, CA: Sage.

Atkinson, P. (1996). Sociological readings and re-readings. Aldershot: Ashgate.

Atkinson, P., Delamont, S., \& Housley, W. (2008). Contours of culture: Complex ethnography and the ethnography of complexity, Lanham, MD: AltaMira Press.

Behar, R., \& Gordon, D. A. (Eds.). (1995). Women writing culture. Berkeley: University of California Press.

Brown, R. H. (1977). A poetic for sociology: Toward a logic of discovery for the human sciences. Cambridge: Cambridge University Press.

Cappetti, C. (1993). Writing Chicago: Modernism, ethnography, and the novel. New York: Columbia University Press.

Carey, J. T. (1975). Sociology and public affairs: The Chicago School. Beverly Hills, CA: Sage.

$\rightarrow$ Clifford, J. (1981). On ethnographic surrealism. Comparative Studies in Society and History, 23, 539-564. doi: 10.1017/S0010417500013554

Clifford, J. (1988). The predicament of culture: Twentieth-century ethnography, literature, and art. Cambridge, MA: Harvard University Press.

Clifford, J., \& Marcus, G. E. (Eds.). (1986). Writing culture: The poetics and politics of ethnography. Berkeley: University of California Press.

Cole, S. (1995). Ruth Landes and the early ethnography of race and gender. In R. Behar \& D. A. Gordon (Eds.), Women writing culture (pp. 166-185). Berkeley: University of California Press.

Dalby, L. C. (1983). Geisha. Berkeley: University of California Press.

Dalby, L. (2000). The tale of Murasaki. London: Chatto \& Windus.

Dalby, L. (2007). East wind melts the ice. London: Chatto \& Windus.

Dicks, B., Mason, B., Coffey, A., \& Atkinson, P. A. (2005). Qualitative research and hypermedia: Ethnography for the digital age. London: Sage.

Edmondson, R. (1984). Rhetoric in sociology. London: Macmillan.

Ellis, C. (2004). The ethnographic "I": A methodological novel about autoethnography. Walnut Creek, CA: AltaMira Press.

Ellis, C., \& Bochner, A. P. (Eds.). (1996). Composing ethnography: Alternative forms of qualitative writing. Walnut Creek, CA: AltaMira Press.

Evans, B. (2005). Before cultures: The ethnographic imagination in American literature, 1865-1920. Chicago: University of Chicago Press.

Gere, C. (2009). Knossos and the prophets of modernism. Chicago: University of Chicago Press.

Goodall, H. L. (2000). Writing the new ethnography. Lanham, MD: AltaMira Press.

Hecht, T. (2006). After life: An ethnographic novel. Durham, NC: Duke University Press.

$\rightarrow$ Hernández, G. (1993). Multiple mediations in Zora Neale Hurston's Mules and Men. Critique of Anthropology, 13, 351-362. doi: 10.1177/0308275X9301300404

Hurdley, R., \& Dicks, B. (2011). In-between practice: Working in the "thirdspace" of sensory and multimodal methodology. Qualitative Research, 11, 277-292. doi: 10.1177/ 1468794111399837

James, A., Hockey, J., \& Dawson, A. (Eds.). (1997). After writing culture: Epistemology and praxis in contemporary anthropology. London: Routledge.

Josipovici, G. (2010). What ever happened to modernism? New Haven, CT: Yale University Press. 
Kelly, J. (2007). Art, ethnography and the life of objects. Manchester: Manchester University Press.

Neumann, M. (1996). Collecting ourselves at the end of the century. In C. Ellis \& A. P. Bochner (Eds.), Composing ethnography: Alternative forms of qualitative writing (pp. 172-198). Walnut Creek, CA: AltaMira Press.

Quinney, R. (1996). Once my father traveled west to California. In C. Ellis \& A. P. Bochner (Eds.), Composing ethnography: Alternative forms of qualitative writing (pp. 357-382). Walnut Creek, CA: AltaMira Press.

Richardson, L. (1996). Speech lessons. In C. Ellis \& A. P. Bochner (Eds.), Composing ethnography: Alternative forms of qualitative writing (pp. 231-239). Walnut Creek, CA: AltaMira Press.

Richardson, L. (1997). Fields of play: Constructing an academic life. New Brunswick, NJ: Rutgers University Press.

Taussig, M. (2011). I swear I saw this: Drawings in fieldwork notebooks, namely my own. Chicago: University of Chicago Press.

Van Maanen, J. (1988). Tales of the field: On writing ethnography. Chicago: University of Chicago Press.

Williams, D. (1974). Icon and image: A study of sacred and secular forms of African classical art. London: Allen Lane.

Williams, D. (2009). Other leopards. Leeds, UK: Peepal Tree Press. (Original work published 1963)

Williams, D. (2010). The third temptation. Leeds, UK: Peepal Tree Press. (Original work published 1968)

Williams, E. A. (2012). The art of Denis Williams. Leeds, UK: Peepal Tree Press.

Williams, C., \& Williams, E. A. (Eds.). (2010). Denis Williams: A life in works: new and collected essays. Amsterdam: Rodopi.

\section{About the Author}

Paul Atkinson is Distinguished Research Professor in sociology at Cardiff University. He is an Academician of the Academy of Social Sciences. Together with Sara Delamont, he edits the journal Qualitative Research. Recent publications include Creating Conditions (with Katie Featherstone), Everyday Arias: An Operatic Ethnography, and Contours of Culture (with Sara Delamont and William Housley). He is currently conducting field research on craft artists. 